\title{
The Comparison of Chinese and American Interpersonal Relationships
}

\author{
Hu Ping \\ School of Foreign Languages \\ Chong Qing Three Gorges University \\ Chongqing, China \\ 366861@qq.com
}

\author{
Tan Yan \\ English Language and Literature \\ Graduate School of SISU \\ Chongqing, China \\ 912256182@qq.com
}

\begin{abstract}
In the course of globalization, the relationships between Chinese and American become closer and closer, and the communication between citizens of both countries is more and more frequent. However, because the culture of Chinese is much different from that of American, so do their attitude towards their family, friends, colleague and boss, and their principles and ways to deal with their interpersonal relationships. In order to make this kind of cross-culture communication go on much more smoothly, it is necessary to explore and learn their differences of interpersonal relationships. Thus, this paper will make a comparison between Chinese and American interpersonal relationships from three aspects, they are the interpersonal relationships existed in family, friends, and working place, and analyze the reasons that contribute to these differences.
\end{abstract}

Keywords-interpersonal relationships; differences; cultural reasons

\section{INTRODUCTION}

Interpersonal relationship is the relationship between people. "From a perspective of social psychology, interpersonal relationship refers to people's psychological relationship, and is the psychological contact that refers to the psychological distance generated by communicative activity"(Jia Yuxin,1997: 156). It is the embodiment of the density of the psychological distance between people, such as intimacy or alienation, even hostile relations. But the principle used to achieve interpersonal relationships in different cultures is different, which leads to the differences of the interpersonal relationships between two countries. A society is composed of social relations where each person gets involved. As all nations in the world have their own outlook, values and social structure, they have their own principles to deal with interpersonal relationships.

I. Analysis of the differences between Chinese and American interpersonal relationships

Every society is composed of many complicated types of interpersonal relationships, which are the things that everyone is bound to live with. And interpersonal relationships can mainly divided into three categories, which are the interpersonal relationships existed in the family, friends and working place. Thus, in order to analyze the differences between Chinese and American interpersonal relationships, it is necessary to find out their differences in these there aspects respectively.

\section{A. The Differences in the Aspect of Family}

There are many different interpersonal relationships existed in the aspect of family. For example, the majority of Chinese family belongs to the large extended family, with several generations all living together. Contrarily, in America, nuclear family which mainly includes parents and unmarried children plays a dominate role. The number of extended family is fewer. Moreover, filial piety is highly praised in China, which is a typical character of China. Being filial to parents is not only a matter of duty, but also a matter of virtue. To some extent, to be filial means to respect and admit the authority of parents, for most of Chinese insist that parents should be superior to their children, and their father is accepted as the pillar and master of the family, all of which is hard to see in the American families. They strongly believe equality exists everywhere, including family. The freedom and independence of children is of great importance in their family, and parents do not have the absolute power. So their relationship is more like friends than kinship, which means their relationship is more independent and equal. These characteristics can been easily found in their daily lives. For example, Children can call the names of their parents directly, and parents often talk to children in a discussing and suggesting way, such as, I suggest ... This is completely different from that of Chinese.

\section{B. The Differences in the Aspect of Friends}

Besides these differences found in the aspect of family, there are many difference of interpersonal relationships in the aspect of friends between China and America. What goes first is their different definition to friend. In Chinese culture, being a friend means they are very close, and this relationship is built through quite a long time. Moreover, friends can deepen into every part of one's life. When in chatting, their topics include personal privacy, such as age and income, which is just regarded as a way of expressing their intimacy and attention. Most Chinese believe that friends should treat each other with all sincerity, and share weal and woe, and should help each other at the cost of everything, even his own life when it is necessary.

Contrarily, Americans may become friends just in one minute; even acquaintance can become a friend. So friend is not to describe a limited group but a very wild range of interpersonal relationships. Moreover, Friendship is viewed as a kind of relaxing relation. What they want is a friendship where they can keep their distinctive character. They don't like their friends depend on them excessively and vice versa. They lay an emphasis on personal profit and often consider 
that business is business, competition is competition, and one shouldn't interfere in public duty with private affairs. Even they are good friends; they have to follow the principle.

\section{The Differences in the Working Place}

Apart from these differences of interpersonal relationships in the aspect of family and friends, many other differences can be found in the working place. Firstly, in China, the interpersonal relationship in working place is much more emotional. They prefer to view their colleagues and boss as friends. When they join in a company, they will have a strong feeling of belongings. They are tightly linked with their colleagues and boss, and they will share the prosperity and decline of the company together, and their success and failure are largely connected with destine of their company, all of which are not forced by laws but driven by the restriction of social morality. Besides, A strict social structure exists in China. Therefore, the principle used to handle the interpersonal relationships in working place is greatly influenced by their social standings. Their relationships are more formal, and they pay much attention to formality and etiquette. For instance, people will use the title as a form of address, and their words are more implicit.

By contract, American more emphasize principle, that they do everything will strictly stick to relevant laws. The relationship between colleagues and boss are kept by contract which carefully describes their rights and duties respectively. They are just partners. What they care about each other is just something limited in work. They have a strong thirst for competition and efficiency, and go in for adventure and achievements. For them, individual interest is much more important than others and groups. Thus, when the company is in danger, most of them will take action quickly and try their best to protect their own interest. This can explain the high rate of job-hopping in America.

\section{THE REASONS THAT CONTRIBUTE TO THESE DIFFERENCES}

By comparison and contrast, many differences of interpersonal relationships that have been shown above had been found. And through reading many books and observing, many elements that contribute to these differences of interpersonal relationships between China and America have been found, including two objective and subjective elements respectively.

The first objective factor is the influence of geography, which greatly influences the culture of a country. The Culture of China originates from the Yellow River. Its main climate is temperate, which is suitable to agricultural cultivation. This makes agriculture become the mainstay of its economy. Most people depend on agriculture, so as to the land, and see agriculture as the main economic support so that the fundamental unit of the country is their families. So their living environment is relatively stable and the cornerstone of society is the patriarchal structure supported by bloody ties. What services for the patriarchal social system is ethics, and family ethics has become one of the typical characteristics of traditional Chinese culture. Obedience to authority and elders is necessary for people.
All of these, more or less, make Chinese form the characteristic of longing for peace, stability and complying with ethics.

In America, the marine environment determines commercial nature of Western culture. Because people live in the marine environment which is not stable, so the population mobility is frequent and the neighborhood composition is relatively not fixed. Compared with China, the development of the commercial economy is much earlier. Therefore, the relationships between people are based on the social contract system which is a feather of urban city, rather than the patriarchal social organization based on blood ties. The original collective cooperation mode of production has long been replaced by the new individual production mode, which makes people get rid of the shackles of kinship network, forming a more democratic, equal relationship. Under these influences, people are indifference to the sense of family, and the relationship between the family and their relatives are not very close.

Apart from this, there is another objective factor that is the difference of their development of history. One of the most obvious differences of the development of history between China and America is the length of history. China has a long history, and feudal rule dominated china for two thousand years, which has a direct impact on the formation of modern values, such as social standing. Thus, they attach great importance to individual identity and act properly. By contrast, in America, the bourgeoisie overthrew the feudal rule and established the capitalist society in early seventeenth century, so they were not strongly affected by feudal thought as Chinese. Moreover, the industrial revolution not only improved the living standard of people, but also set the thinking of people freed, let them learn how to respect others and yearn for freedom and equality.

Besides that, the length of history also has a strong influence on its people's attitude and orientation in viewing time. Time orientation of Chinese is looking backward, while Americans are looking forward. Chinese history is very long and profound, so people attach great importance to the traditional successful experience and lessons and precedent, and turn to them for guidance about how the former to do this. By contrast, time orientation of Americans is to look forward, focusing on the future. Maybe they are in an immigrant society, which itself is not rich in traditional culture and heritage, so the burden that comes from their tradition is little. In addition, their culture is greatly affected by The Bible, which started from the Original Sin. Therefore, they are unwilling to return to the past, and looking back is to go back to the Original Sin. What they can only do is to continue to repent, work hard and face the future (Mellen, 2002: 57).

Besides these objective reasons, there are two subjective reasons. The first one is their different interpersonal relation orientation. It is generated by their different ancient philosophy which is dominated by Confucianism in China, and which is greatly influenced by religion and Renaissance in western countries.

Chinese stress on collectivism, and Confucianism is the representative of traditional Chinese culture. "The main 
assertion of it is that every one of the society should put a priority to the interests of family, society and nation, even at the cast of personal interests when it is necessary" (Zhang Junqiang, 2007:13). This doctrine has been passing from generation to generation and become ingrained. They are used to giving collectivity a priority. While Americans more emphasize on individualism, there are many elements that contribute to this phenomenon, such as religion Renaissance and ancient philosophy. For instance, the Renaissance which started in Italy in the end of thirteenth century set people free from the shackle of religion, began to stress on the liberation and freedom of personality, and encouraged common people to peruse their own happiness and interests (Luo Jingguo, 1996:67), all of which have laid a fundamental condition to the formation on individualism.

In addition, there is another subjective factor that needs to be mentioned, that is their different ways of thinking. Ways of thinking is greatly affected by national philosophy. Chinese are more likely to be emotional, while Americans are more rational. In Chinese, Confucianism, Taoism and Buddhism have great influence on the formation of way of thinking. These three all lay a great emphasis on savvy, so what one does and how he behaves are a more subtle and tactful process to let others get his true meaning through careful thinking, thus there is much more subjective factor in one's thinking. For example, praising someone does not mean the praised is really worthy of it, for there are many subjective factors involved, such as she is beautiful. While the philosophical background of Europe and the United States is the rigorous logic of Aristotle, which stress logical thinking and rationalism that pays much attention to argumentation, promoting the development of Natural Science. Thus their behavior is more straightforward and logic.

\section{CONCLUSION}

With the non-stopping development of globalization, international communication becomes more frequent. And in this process, more and more conflicts that are caused by their different culture background are found. In order to eliminate misunderstanding, and promote communication and cooperation, it is deadly important to understand these differences. For this goal, this paper analyses the difference between Chinese and American interpersonal relationships from three aspects firstly. And then, with wilder and deeper study on this topic, some objective and subjective reasons that contribute to these differences are found. Understanding all of these that have mentioned above, the consciousness of cross-culture communication would largely increased, which would not only make the international communication between people from these two countries more smoothly, but also lay a fundamental condition for a more mutual understanding between countries and more peaceful world.

\section{REFERENCES}

[1] Jia Yuxin, Intercultural Communication,Shanghai: Shanghai Foreign Language Education Press, 1997, pp.151-157.(In Chinese)

[2] Luo Jingguo, Selected readings in English Literature, 3rd ed., Peking : Peking Press, 1996, pp.65-68.(In Chinese)

[3] Mellen, "On Display and Difference of Value Outlook between China and and Western Countries", Zhejiang: Journal of Zhejiang Shuren University(Humanities and Social Sciences), 2002, pp.55-60.

[4] Zhang Congyi, A comparative study of Chinese and Western culture, Hunan : Hunan People's Publishing House, 2007, pp.22-26.(In Chinese)

[5] Zhang Junqiang, "The Enlightenment of Confucius benevolence to Modern Society", HeBei: Journal of Hengshui University, 2007, PP.12-17.(In Chinese) 